\title{
SociabiLIDADE E COTIDIANO NA PERIFERIA DE LONDRINA*
}

\author{
Ana Cristina Silva Santos \\ Mestranda em Ciências Sociais \\ na Universidade Estadual ed Londrina \\ E-mail: analondrina@ hotmail.com
}

"A monotonia da vida cotidiana sempre oprimiu a humanidade pesando sobre ela como $\mathrm{um}$ rochedo. Já os gregos simbolizavam no mito de Sísifo - labor da via diária incessantemente recomeçado. A rotina do dia-a-dia é, em geral, considerada desimportante, mas até que ponto esse cotidiano tão desprezado e desprezível não influi nas grandes decisões que modificam a História ou não constitui, ele mesmo, a História?"

(LEFEBVRE, 1972)

\section{Resumo}

O presente artigo refere-se à uma pesquisa sobre a estruturação de redes de sociabilidade entre moradores de periferia da cidade de Londrina - PR. A intenção é a de enfatizar como as dimensões sociabilidade e cotidiano emergem como categorias sociológicas importantes nos estudos sobre periferia.

Palavas-chave: cotidiano; periferia; sociabilidade.

nálises sobre a vida cotidiana têm atualmente despertado interesse entre diversos estudiosos não só das áreas de Sociologia e Antropologia, como também de História e Filosofia.

Como exemplo, tem-se a corrente conhecida como "Nova História", a qual aponta para a necessidade de dirigir os estudos para o

O presente artigo refere-se às discussões efetuadas em minha monografia de conclusão de curso de Bacharelado em Ciências Sociais na UEL, em 2002. 
homem comum e seu contexto, dando espaço para a história do cotidiano e das mentalidades. Essa corrente enfatiza a vida privada, ou seja, os usos e costumes dos povos numa perspectiva da rotina diária. Na Filosofia conhecemos, entre outras, as análises realizadas por Henri Lefebvre e Ágnes Heller, enfatizando a importância de estudos sobre a vida cotidiana com a finalidade de compreender a reprodução da vida social. São análises que, em geral, se voltam para a existência do homem comum, para os ambientes de pequena escala (grupos de parentesco, vizinhança, família, entre outros), para os sistemas de interação, voltam-se enfim, para um cotidiano compartilhado ${ }^{2}$.

$\mathrm{Na}$ Sociologia, análises da vida cotidiana ${ }^{3}$, muitas vezes, acabam por estabelecer fronteiras tênues com a Antropologia, ao realizar um trabalho etnográfico privilegiando grupos de pequena escala transitando tanto entre as circunstâncias mais específicas e particulares quanto entre as mais gerais da reprodução da vida social. São estudos que, também, privilegiam os espaços intersticiais e as redes de relações sociais, tornando-se, portanto, preciosas pistas para um entendimento de como grupos sociais se organizam valendo-se da vivência do dia a dia.

Segundo Martins (1997, 1998) , essas análises sociológicas sobre a vida cotidiana se voltam para um fenômeno muito recente: a cotidinanidade.

' Entre alguns expoentes desta corrente, estão Marc Bloch, Lucien Febvre e Jacques Le Goff.

${ }^{2}$ Cabe ressaltar que na Literatura os escritos de Joyce, Balzac, Flaubert. entre outros, já se voltam para as facetas da cotidianidade (LEFEBVRE, 1972).

${ }^{3}$ Entre estudos sobre cotidiano no âmbito da Sociologia temos duas correntes principais, a fenomenologia e a vertente marxista. No interior da primeira corrente, há subdivisões, como é possível perceber ao se deparar com o presentismo formista de Michel Maffesoli; Alfred Schutz, um dos teóricos que influencia diretamente Peter Berger e Thomas Luckmann, estes elaborando a chamada sociologia do conhecimento; o interacionismo simbólico de Erving Goffman e a etnometodologia, tendo como principal representante Garfinkel. entre outros estudiosos do tema. Enquanto que na tradição marxista temos George Lukács que, por sua vez, influencia Ágnes Heller, e Henri Lefebvre. ( José de Souza Martins, O Senso Comum e a Vida Cotidiana, 1998 e João Carlos Tedesco, Paradigmas do Cotidiano, 1999).

+ A exemplo, sobretudo. de Henri Lefebvre. 
"(...) o aparecimento da cotidianidade é a transformação da realidade social numa realidade de manipulação, de escamoteamento, de alienação moderna, alienação levada ao extremo de suas possibilidades de mistificação da vida" (MARTINS, 1997, p.58).

A fim de compreender esse fenômeno e, também, como os indivíduos buscam formas para transformá-lo, surgem estudos interessados no conhecimento do senso comum, isto é, sobre um conhecimento compartilhado por muitos indivíduos que, no dia-a-dia, através de suas práticas sociais, buscam a renovação da sociedade.

Análises da vida cotidiana na contemporaneidade surgem, portanto, como formas de interpretar o mundo moderno sob nova ótica, diversa daquela que privilegia somente as questões estruturais ou institucionais, pois a construção das relações sociais pode e deve também ser verificada a partir do conhecimento do dia-a-dia (MARTINS, 1997) e em grupos menores. Se existem limitações relativas ao estudo de alguns aspectos da estrutura social no âmbito de uma pequena escala desta estrutura, há também vantagens, pois:

"(...) o uso de uma pequena unidade social como foco de investigação de problemas igualmente encontráveis numa grande variedade de unidades sociais, maiores e mais diferenciadas, possibilita a exploração desses problemas com uma minúcia considerável - microscopicamente, por assim dizer." (ELIAS, 2000, p.20)

\section{Sociabilidade e cotidiano como categorias analíticas em estudos sobre periferia}

No presente, vida cotidiana, sociabilidade e periferia emergem como dimensões interdependentes e indissociáveis, entendendo-se que periferia não é somente uma referência geográfica, ou seja, um lugar distante do centro da cidade, mas também um lugar onde há precariedade de recursos e, portanto, onde reside a população mais pobre - entenda-se precariedade a deficiência no transporte, nos serviços públicos e na infra-estrutura - Geralmente são lugares de difícil acesso, por se situarem em áreas insalubres ou de topografia desfavorável (CALDEIRA, 1984). Para Nestor Razente (1982, p.278), a origem do espaço periférico reside: 
“(...) na lógica social maior subjacente ao desenvolvimento capitalista brasileiro onde, a exigência de aglomeração da força de trabalho, impôs novos padrões de produção e ocupação do espaço localizado nas franjas da cidade."

As periferias são lugares "inóspitos e miseráveis", onde se verifica, de forma muito clara, a segregação social e espacial, apesar de existirem populações pobres em muitos outros lugares. Mas é na periferia que se concentram indivíduos que transformam o local onde moram em expressão mais clara de seu modo de vida. É por isso que a periferia é tomada, neste artigo, como um espaço onde também são construídos significados e estruturada uma sociabilidade, através de um cotidiano compartilhado.

Realmente existe uma enorme diversidade entre a população residente em periferias, composta, geralmente, por operários, autônomos, empregadas domésticas e pequenos funcionários públicos, portanto, grupos profissionais ligados a funções de pouco prestígio e baixa remuneração. Apesar dessa diversidade, esses indivíduos vivenciam uma maneira específica de ser e viver, através da qual constroem uma visão mais ampla da sociedade ${ }^{5}$. Dessa maneira, supõe-se que exista uma identificação de valores, hábitos, gostos e aspirações. Ou seja, um estilo de vida e uma sociabilidade próprios, com uma determinada rotina e um cotidiano específico. São:“(...) elementos que conferem um caráter particular ao espaço do bairro" e "(...) estão intrinsecamente ligados ao tipo de sociabilidade e de comunicabilidade que aí existe entre as pessoas (...)"'(CALDEIRA, 1984, p.120)

Entre diversas explicações sobre a formação de bairros periféricos há também aquela que justifica a existência da periferia como forma de solucionar o problema de habitação para os trabalhadores de baixa renda, em razão da deteriorização das condições de vida ocasionada por

'Eunice Durham (1986) “A Sociedade vista da Periferia”, 1986. Trata-se de um estudo realizado no Centro Brasileiro de Análise e Planejamento (CEBRAP), em 1982, por um grupo de antropólogos da USP sobre a visão que moradores de periferia têm da sociedade, onde são traçadas algumas características gerais sobre estes locais e seus habitantes a partir das condições observadas em cidades de grande e médio porte.

- CTNP: empresa de caráter privado subsidiária da empresa inglesa "Paraná Plantation Ltda", sediada em Londres. 
um modo de produção que faz com que sejam perpetuadas as desigualdades sociais e a acumulação do capital.

Já no início de sua formação, a cidade de Londrina se expande demográfica e economicamente com espantosa rapidez, permanecendo, porém, ainda dentro do espaço planejado pela CTNP -Companhia de Terras Norte do Paraná -, agente imobiliário e responsável pela colonização da região ${ }^{6}$. Essa expansão se deu principalmente devido à atividade econômica cafeeira, transformando Londrina e outras cidades do território colonizado em importantes centros prestadores de serviços ao meio rural?

No final de 1930, quando a Companhia deixa de ser a única empresa loteadora, começam a surgir ocupações de áreas que estavam fora do planejamento do grupo inglês, como a Vila Matarazzo, formada em 1937 (ADUM, 1991).

"Trata-se do momento importante para a configuração do espaço urbano de Londrina. A quebra do monopólio na produção da terra, significa: a introdução de novos competidores no mercado; estabelecimento de uma taxa média de lucro no mercado fundiário; a localização espacial comandada pela pluralidade de agentes produtores do espaço; e a aparente perda do domínio de expansão da cidade (...)"(RAZENTE, 1982, p.246)

Na década de 50, já eram incorporados à área urbana da cidade mais 67 novos loteamentos, provocando um crescimento acelerado, que gerou diversos problemas para o município. Segundo Adum (1991), esse processo acabou por acarretar:

“(...) uma ocupação do espaço sem qualquer critério estabelecido, sem técnicas, sem planos, isto é, sem qualquer conexão com

\footnotetext{
'Sobre a história da formação do município de Londrina, temos à disposição uma rica e diversificada bibliografia especializada a qual procura mostrar, sob diferentes enfoques, tal processo. Entre diversos autores, temos Sônia Adum, Imagens do Progiesso: Civilização e Barbárie em Londrina - 1930/1960, 1991; Ana Maria Chiarotui de Almeida, A Morada do Vale. Londrina, 1997; José Miguel Arias Neto, O Eldorado: Londrina e o Norte do Paranci - 1930/1975, 1998; Nestor Razente, Ocupação do Espaço Urbano de Londrina, 1982; Ricardo de Jesus Silveira, As Associações de Moradores e a Construção do Espaço Público: um exercício de cidudunia. 1997; Nelson Tomazi, Certeza de lucro e direito de propriedade - o mito da Companhia de Terras Norte do Paraná, 1989, entre outros.
} 
a malha viária existente. Quer dizer, o crescimento do sítio urbano não foi acompanhado pela presença de equipamentos de consumo coletivo, que permitisse que a força de trabalho disposta nestes novos espaços fosse atendida (...)"

A cidade de Londrina passa a sofrer alterações em sua estrutura urbana, não-condizentes com aquela imagem de cidade salubre, enfatizada pelos seus colonizadores (SILVEIRA, 1997). Na verdade, torna-se explícita a ação do especulador imobiliário, que se enriquece com a venda de lotes urbanos aos migrantes que, expulsos, em maior número, do campo, chegam à cidade, ocupando os espaços de forma desordenada.

Para tentar ordenar a cidade, o poder público local implementou a primeira lei de zoneamento urbano, a Lei 133, de 1952, que apresenta, aliadas a medidas de profilaxia urbana, as diretrizes para a organização de loteamentos, construção de casas, arborização, construção de praças públicas, arruamentos, dentro de uma meta de crescimento a longo prazo.

Com essa lei, pretendeu-se dividir o espaço em zonas urbanísticas: residencial, comercial, industrial, ferroviária e rural. Porém, de acordo com Razente (1982, p.264), essa lei favoreceu a estratificação social, segregando o espaço em conformidade com as classes sociais que a ocupam:

"O ordenamento espacial entre os anos 50 e 60 representam estas novas preocupações com o espaço. De fato, o conjunto jurídico implicava até na diferenciação física dos lotes urbanos: maior área para a classe de maior renda; menor renda, menor disponibilidade de terra".

A partir da década de 70, a política habitacional adotada pelo Poder Público Municipal, aliada à iniciativa privada de loteamento de terrenos em torno do núcleo ocupou-se em construir conjuntos habitacionais e em regularizar áreas urbanas invadidas, o que resultou no crescimento de áreas com características muito próximas às encontradas por Caldeira (1984) e Durham (1986) em suas pesquisas, as quais serviram de base para minhas discussões. Ou seja, "bairros periféricos" distantes do centro da cidade, onde prevalecem a pobreza, a precariedade de recursos e infra-estrutura, bem como a segregação social e espa- 
cial, conferindo aos seus habitantes condições de existência muito semelhantes. Ainda segundo Razente (1982, p.278):

"A periferia londrinense se define, assim, como espaços urbanos onde os chamados "serviços de urbanização" ainda não se mostram presentes, tanto ao nível individual quanto coletivo. São justamente estes espaços urbanos que estiveram abrigando a população migrante campesina.”.

Na rotina do dia-a-dia os moradores, ao usarem e percorrerem o bairro em que vivem, se apropriam desse espaço, privatizando-o. Nesse caso a relação social que predomina é a de vizinhança, ou seja, ao mesmo tempo que possui uma peculiaridade, esta caracteriza-se como uma sociabilidade com aspectos ambígüos, pois os indivíduos, não obstante viverem próximos uns dos outros, estão ao mesmo tempo distantes. $\mathrm{Ou}$ seja, apesar do vizinho não ser um desconhecido, não é tratado de maneira fraterna ou íntima, como ocorre entre membros de uma mesma família. (CALDEIRA, 1984; MARTINS, 1999).

A tendência nas relações de vizinhança implica uma identificação dos indivíduos com o local onde moram, porquanto este torna-se importante referência em sua apresentação para o mundo (MARTINS, 1999). Há um "consenso operacional" que consiste num:

“(...) acordo real quanto às pretensões de qual pessoa, referente a quais questões, que serão temporariamente acatadas. Haverá também um acordo real quanto à conveniência de se evitar um conflito aberto de definições de situação.'(GOFFMAN, 1985, p.18)

Para entender o comportamento dos moradores de periferia, bem como a estruturação das relações sociais, nos remetemos ao estudo de Erving Goffman (1985) exposto na obra A Representação do Eu na Vida Cotidiana. Esse autor utiliza a linguagem teatral para analisar os processos de interação social, acreditando que um sociólogo tem condições de compreender o padrão de interação de um grupo através da observação das desarmonias entre os atores que representam uma cena. Suas explicações demonstram que as relações sociais estão permeadas de uma "dramática atividade de simulação e teatralização", possibilitando que seu significado seja produzido/reconhecido na interação social 
e que não ocasione descrédito para o sujeito. Assim, segundo esse autor, na vida em sociedade, os indivíduos estão sempre representando papéis de atores principais e de coadjuvantes.

Dessa maneira, os indivíduos estão, cotidianamente, se identificando através de um sistema de interação construído em ambientes de pequena escala (grupos de parentesco, vizinhança, família, entre outros) e construindo sua existência social. Pensando, portanto, tanto nas circunstâncias mais específicas quanto nas mais gerais da reprodução da vida social, podemos entender tal com Heller que o cotidiano implica um " $(\ldots)$ conjunto de atividades que caracterizam a reprodução dos homens particulares, os quais, por sua vez, criam a possibilidade da reprodução social" (HELLER, 1989, p.19). Essa autora entende a vida cotidiana como a vida do "homem inteiro", visto que o homem participa na vida cotidiana com todos os elementos de sua individualidade e de sua personalidade. Porém, apesar de se tratar da vida do indivíduo, Heller chama a atenção para o fato deste indivíduo ser, ao mesmo tempo, um "ser particular" e um "ser genérico", isto porque o sujeito da vida cotidiana é um ser humano que age como uma totalidade (HELLER, 1989; GRANJO, 1996).

Ao discutir esses autores, a intenção, no presente, é chamar a atenção para a necessidade de considerar que é no cotidiano que os indivíduos vivem, estruturam uma determinada sociabilidade, constroem suas identidades e desempenham papéis. É através do cotidiano que valores são compartilhados de uma maneira que parece "natural", pois não se trata de padrões, ou normas, que são conscientemente determinados por cada um e, sim, justamente reiterados no dia-a-dia (CALDEIRA, 1984). Assim, os estilos de vida e papéis observados no cotidiano são apresentados como fragmentos e tarefas que se executam de maneira quase automática. Dessa forma, o cotidiano acaba se tornando uma vivência de um "outro tempo", que definitivamente não é aquele que prevalece e que é valorizado em nossa sociedade, pois que, como afirma Lefebvre (1972, p.36):

"O cotidiano é o humilde e o sólido, o que se dá por suposto, aquilo cujas partes e fragmentos se encadeiam em um emprego do tempo. E isso sem que alguém (o interessado) tenha que examinar as articulações dessas partes. É o que não leva data. É o insignificante (aparentemente); ocupa e preocupa e, no entan- 
to, não tem necessidade de ser dito, ética subjacente ao emprego do tempo, estética da decoração do tempo empregado".

Enquanto a noção de tempo que prevalece no cotidiano é repetitiva e cíclica, uma vez que se inicia, termina e recomeça da mesma forma, acabando por não possuir profundidade - não tem nem passado nem futuro -, nas sociedades contemporâneas temos a noção de um tempo linear.(CALDEIRA, 1984). Elias (1998, p.33), em sua obra Sobre o Tempo, ao propor uma análise de como se estıuturam e se direcionam as mudanças ocorridas através da experiência humana acerca do que chamamos de "tempo", considera:

“(...) a percepção do tempo exige centros de perspectiva - os seres humanos - capazes de elaborar uma imagem mental em que eventos sucessivos A, B e C, estejam presentes em conjunto, embora sejam claramente reconhecidos como não simultâneos. Ela pressupõe seres dotados de um poder de síntese acionado e estruturado pela experiência. Esse poder de síntese constitui uma especificidade da espécie humana. (...) É nessa capacidade de aprender com experiências transmitidas de uma geração para outra que repousam o aprimoramento e a ampliação progressivos dos meios humanos de orientação, no correr dos séculos.(...) É essa função de meio de orientação que hoje concebemos e experimentamos como sendo o 'tempo'."

A temporalidade é, então, uma questão primordial na discussão sobre o cotidiano, assim como também a sua estruturação espaci$\mathrm{al}^{\lessgtr}$. Porém, não constitui objetivo deste artigo aprofundar esses aspectos, visto que nossas discussões acentuam a compreensão das redes de sociabilidade estruturadas no cotidiano. Ou seja, como esse

\& Tempo e espaço constituem dimensões indispensáveis à análise do cotidiano. Em termos gerais, existem diferentes tempos sociais que são distintos do tempo biológico e psíguico. assim como o espaço social é distinto do geométrico, geográfico e econômico: "A vida cotidiana parece estar, na verdade, estruturada por ciclos: ciclo diário. semanal, anual, das estações (esse principalmente para o camponês), ciclos de emprego, de desemprego, de saúde/doença, de juventude, de velhice, de renovação de gerações, etc. em razão dos ciclos, as pessoas e os grupos se organizam e se previnem, suas vicissitudes, práticas, resignações e confiança colaboram para criar um modo de vida“(BERTEAUX apud TEDESCO, 1999, p.180). 
processo se realiza de uma maneira não consciente através das relações sociais estabelecidas no local de moradia, conferindo aos habitantes da periferia um jeito de ser e viver, diferente de outros locais da cidade (DURHAM, 1986).

A ênfase, portanto, está na participação do "homem comum", portador de um "senso comum", e considerado como um agente da dinâmica social apesar de imerso numa cotidianidade (MARTINS, 1998: 1999). Aquele homem de carne, osso e sonhos que, compelido pelas circunstâncias, age no sentido de procurar obter o que falta a ele, ou seja, aquilo que faz parte das suas "necessidades básicas", tanto de natureza material (abrigo, proteção, alimentação) quanto não-material, pela natureza qualitativa de sua satisfação (MARTINS, 1998).

Heller (apud GRANJO, 1996), ao desenvolver a "Teoria das Necessidades Radicais", enfatiza justamente a natureza qualitativa dessas necessidades na modernidade, demonstrando que " (...) o que distingue as necessidades radicais é o fato de representarem a singularidade e idiossincrasia de pessoas e comunidades." (HELLER apud GRANJO, 1996, p.59) Porém, nas sociedades atuais essas necessidades ainda não podem ser satisfeitas totalmente, uma vez que temos uma sociedade superordenada, onde impera a subordinação?.

Ainda, segundo Heller (apud GRANJO,1996), as necessidades radicais não substituem estas outras necessidades relativas a elementos materiais, antes as contrabalançam. E para esta autora, somente quem possui necessidades radicais pode desejar a transformação de sua vida. São necessidades que "(...)ganham sentido na falta de sentido da vida cotidiana." (MARTINS, 1998, p.6) E é só para quem a vida cotidiana se tornou insuportável que isso se torna possível, pois esta vida já não pode mais ser manipulada.

\footnotetext{
" Heller se refere aqui ao sujeito da história não mais necessariamente como o proletariado, e sim como todo o grupo portador de necessidades radicais. Para a autora, a construção do paraíso é impossível e, dessa forma, não acredita que o sistema socioeconômico da modernidade tenha condições de ser negado por completo e enfim substituído por uma situação em que haja liberdade e onde não exista hierarquia de dominação ou conflitos sociais. O que poderia ser feito, no entanto, é a melhoria das condições socioeconômicas, constituindo. pelo menos. uma diminuição da distância entre as necessidades e a possibilidade de sua satisfação (GRANJO, 1996).
} 
Por isso, pretendemos, durante a pesquisa efetuada em três bairros da periferia de Londrina (Jardim Franciscato, Perobal e Novo Perobal), localizados na zona sul, fazer com que a análise do cotidiano de seus moradores seja realizada tal como Martins (1997) e Caldeira (1984) propõem, ou seja, pretendemos observar "de perto" esse cotidiano, vivenciando, na medida do possível, o dia-a-dia das pessoas do local, estando junto a elas, em suas residências, pelas ruas dos bairros, nas festividades, etc. Pretendemos, enfim, seguir sobretudo a linha de uma análise "microscópica", como nos orienta Geertz (1978), trabalhando com as informações obtidas através de inúmeras conversas com estas pessoas e, também, com as impressões que ficaram, procurando registrar o maior número possível de acontecimentos, mas tendo sempre em mente que o pesquisador não passa de um "outro", um alguém "de fora" e que os moradores têm plena consciência desta distinção. (CALDEIRA, 1984)

"A história do cotidiano não tem sentido quando separada do cenário em que se derenrola. Por isso, é quase uma história intimista, de vizinhanças e pequenos grupos (...) implica em lidar com o tempo numa escala muito fragmentária, o que impõe ao pesquisador a preocupação com o detalhe e a minúcia." (MARTINS, 1992, p.19)

\section{O dia a dia dos moradores da periferia de londrina: um estudo de caso}

Seguindo a opção teórico-metodológica .discutida anteriormente, durante oito meses de pesquisa procuramos observar o cotidiano dos moradores dos bairros Jardim Franciscato, Jardim Perobal e

\footnotetext{
10 Jd.Franciscato: O terreno, propriedade particular, foi ocupado em 1978, com a chegada de 4 famulias que não tinham condições de continuar pagando aluguel oriundas de propriedades rurais e, após 2 anos chegaram ao local mais algumas dezenas de familias; Jd.Perobal : A área foi ocupada em 1986 por 8 famílias do "Movimento Sem Terra" e para esses indivíduos houve da parte da COAB-LD um compromisso de construir casas;Jd.Novo Perobal: Esta área, que foi ocupada da mesma maneira que os dois outros bairros citados acima, pertencia à COHAB-LD. Sua doação foi efetivada através de escritura pública, tendo como outorgante doador o Município de Londrina, quando tinha Antônio Belinati como prefeito.
} 
Jardim Novo Perobal ${ }^{10}$, frequentando a Escola- Oficina "Pestalozzi" "1, visitando as casas, creche e outros locais, realizando o mesmo trajeto do ônibus urbano, conversando com os habitantes das localidades e entrevistando três destes moradores: Rosângela, Maria e Paulo '? A escolha dessas pessoas deu-se em razão de alguns aspectos em comum entre elas. Além de residerem no local onde foi desenvolvida a pesquisa, prestam ou prestaram serviços à Escola (de forma remunerada e não-remunerada). Para o registro dessas observações foi utilizado um diário de campo e, para as entrevistas, um gravador. As entrevistas (de caráter qualitativo), seguiram um roteiro previamente elaborado com a finalidade de conhecer um pouco da história e trajetória de vida dos informantes, assim como suas relações com o bairro, a vizinhança e as instituições.

No decorrer deste trabalho, cuja proposta consistiu em verificar a estruturação da sociabilidade dos moradores da região formada por esses três bairros enfatizando o complexo de interações existentes e observáveis a partir de uma análise da vida cotidiana dos indivíduos, foi possível constatar o que havia sido lançado como pressuposto inicial. Ou seja, os indivíduos estruturam um tipo de sociabilidade tendo em vista o cotidiano específico que vivenciam.

"Como ponto de partida desta pesquisa, a instituição localizada na região é compreendida pelos três bairros citados, que desenvolve atividades junto à comunidade sem fins lucrativos. Sua fundação se deu em 31 de março de 1997 e tem como diretora, a pedagoga aposentada Maria Eloísa Ferreira que, como a maior parte das pessoas que atuam na entidade, é voluntária. A Escola se mantém com verbas enviadas por empreśŕrios alemães, através de um convênio, da Prefeitura Municipal de Londrina. através da Secretaria de Ação Social e, também com doações de seus mantenedores e empresariado local. As atividades oferecidas vão desde modalidades esportivas futebol de salão, volei, capoeira, entre outras - até teatro, educação artística. reforço escolar e cursos profissionalizantes, disponíveis aos jovens residentes na região. A Escola-Oficina "Pestalozzi" é fruto da iniciativa de un grupo de espíritas do Centro Espírita Nossa Lar, de Londrina, que formou a Comunhão Espírita. atuando em programas assistencialistas nos referidos bairros.

12 Rosângela tem 21 anos, dona de casa, casada, tem 2 filhos. Prestou serviços de limpeza na Escola em troca de material de construção para sua casa: Dona Maria. 48, trabalha na limpeza da Escola, é remunerada e teve também sua casa construída com material cedido pelo programa assistencialista, é viúva e tem 4 filhos: Paulo. 20 anos, professor voluntário de capoeira na Escola, é funcionário do Hipermercado Carrefour. 
Dito de outro maneira, uma sociabilidade marcada pelas relações interpessoais, de vizinhança, lealdades e troca de favores, no espaço do bairro, através de suas instituições. Rosângela, Dona Maria e Paulo, os principais informantes, apesar das especificidades quanto às trajetórias de vida, ocupações e estratégias de sobrevivência, têm em comum o fato de manterem relações muito estreitas com a Escola-Oficina "Pestalozzi". Além de vivenciarem o dia-a-dia do bairro, há entre eles uma identificação de valores, hábitos e estilo de vida, resultando num tipo específico de sociabilidade, com ênfase nas relações de lealdade, vizinhança e contatos diretos.

Assim como Caldeira (1984) e Durham (1986) descreveram, em seus trabalhos realizados sobre periferia, neste trabalho foi possível perceber semelhanças quanto à miserabilidade e ao cotidiano dos moradores dos bairros pesquisados. Quanto a alguns aspectos gerais, Rosângela nos dá uma idéia de como era viver no Jardim Novo Perobal anos atrás:

"No início, quando nós mudamos pra cá, a gente não tinha água, não tinha luz. A nossa casa era um cômodo (...). Não tinha..., não tinha ladril, era terra pura, minava água dentro, né. Chovia e enchia de chuva também. E nós lavávamos roupa e tomava banho no rio lá embaixo. Nesse tempo não me lembro se lá era Córrego ou se já..., se já corria resto de esgoto, né. E pra gente não tinha luz, né. Asfalto não tinha, era terra pura, quando chovia assim,(...) que a gente ia assim ia pra sair, pra ir pra algum lugar, a gente atolava no barro que era bem fundo, a gente atolava no barro."(Rosângela)

Quando não havia asfalto (o qual foi concluído no final de 1997), a cada chuva, os moradores enfrentavam muitas dificuldades, pois além de terem que caminhar no barro, tinham que subir uma longa ladeira para terem acesso ao transporte coletivo. Hoje é diferente, porém uma das maiores dificuldades que persiste no cotidiano dos bairros continua sendo a precariedade, ou seja, mesmo com o asfalto, em dias de chuva e frio, os moradores, muitos com suas casas ainda inacabadas ou ainda vivendo em barracos, encontram dificuldades por causa das enxurradas, do barro nos quintais e convivem também com os entulhos (muitas vezes invadindo as casas), com os insetos, além de outros problemas. 
Atualmente, os três bairros têm todas as ruas asfaltadas, energia elétrica e água encanada. Desfrutando agora de melhores condições de infra-estrutura e segurança, Paulo se recorda de alguns períodos de dificuldades financeiras enfrentados pela sua família:

“(...) nossa, já tivemos vários problemas assim de falta de luze égua. Uma vez teve até que... eu tava em São Paulo ainda... teve, cortaram nossa água, nossa luz, tudo assim no mesmo dia (...) Porque eu tava lá, assim trabalhando, né, mas teve uma vez que não deu pra mandar dinheiro pra casa, né... aí "eles" cortaram." (Paulo)

A maior parte da população residente nessa região ainda convive com a precariedade socioeconômica e com a "fama"13 de servir de abrigo a criminosos - traficantes de drogas, assassinos e assaltantes. Além disso, num passado muito recente a população sofria também cotidianamente com a violência da polícia:

"A violência, em vista de... assim, antes assim, acho que agora melhorou bastante, né. Porque antes, a gente via muita violência. Tinha tiroteio. Roubo assim não acontecia muito. Mais tiroteio. Lembro até uma vez que, veio polícia aqui, bateu geral, tirou nós assim, às quatro horas da madrugada, fez todo mundo sair de casa, revirou a casa de todo mundo (...). Eu era pequeno. Revirou a casa de todo mundo, levou várias pessoas presa, acho que a maior violência é... tipo assim, eles tavam procurando droga, procurando marginal e..., agora que deu uma melhorada boa, que veio o asfalto agora, a maioria desses pessoal, desses pessoal assim, mais bandidão que tava aqui, muitos tão preso, muitos tão morto. Acho que agora, agora em vista de antes, vixe, tá cem por cento melhor mesmo. A violência aqui parou." (Paulo)

O que tem sido possível perceber, por observações e informações, é que, atualmente, a região revela uma realidade com muitas outras nuances. No depoimento de Paulo, por exemplo, verificamos que, apesar de uma infância muito pobre e de pertencer a uma família

1.3 Esta "fama", de acordo com as pessoas com quem conversamos, foi conquistada através dos noticiários veiculados nos meios de comunicação da cidade que. apesar de verídicos, muitas vezes se mostravam sensacionalistas. 
que invadiu, juntamente com outras, as terras do Jardim Franciscato, fixando-se ali com inúmeros riscos, ele ainda encontrou um espaço possível de sobrevivência através da capoeira, lutando pela construção de um projeto de vida.

Através do estudo, também, pensa ser possível romper com a carência socioeconômica e, por isso, pretende terminar o ensino médio e, talvez, prestar vestibular para um curso ainda não definido: “( ... eu penso assim, de simplesmente terminar meus estudo, terminar. Aí quem sabe mais pra frente assim... fazer um... como se diz..., um vestibular." (Paulo)

Sobre o seu dia-a-dia durante a semana, nos conta:

"(...) acordo lá pelas seis e meia. Até chegar no Carrefour, são umas sete horas. Eu entro às sete horas. Aí chego, faço meu trabalho. Daí saio às três. E daí, às três horas, quando não tem capoeira aqui na "Pestalozzi"..., ou então estudo, fico em casa estudando(...) E quando tem curso eu fico aqui, e às sete horas da noite eu vou pro colégio.’'(Paulo)

A rotina diária de Paulo é baseada, sobretudo, em seu trabalho e nos estudos. Há, também, o compromisso com a Escola "Pestalozzi" e com a Igreja que freqüienta. Ele é católico e faz parte do grupo de jovens que possui uma banda musical que se apresenta em missas e festas promovidas junto à comunidade local, sendo os ensaios realizados nos finais de semana na igreja localizada no próprio bairro (Jardim Franciscato): “(...) nas missas que nós se apresenta. Nós ensaia pra música da missa e música pra fora também (...)" (Paulo)

Apesar da diversidade de compromissos, ele reconhece a situação em que vivem as pessoas do bairro que não gozam dos mesmos meios de sobrevivência que ele, e enfatiza a necessidade da solidariedade e ajuda mútua: "Existem muitas pessoas desempregadas (...) sempre que eu chego do meu serviço, eu vejo, tô sempre procurando ajudar o próximo, né (...)." (Paulo)

Em momento algum deixa transparecer possíveis desentendimentos com vizinhos ou com qualquer outra pessoa residente na região, 
dizendo: "Não existe encrenca nenhuma (...) não, não tem problema com conflito nenhum não..." (Paulo). Também no que diz respeito à violência no bairro, nada demonstra em seus relatos. Pelo contrário, acentua a solidariedade presente entre os indivíduos daquela região:

"Os vizinho são muito legal mesmo. São antigos aqui, que nem eu. Conheço o pessoal faz tempo. Muito simpático os meus vizinho... eu vou na casa dos vizinho, vou lá, tomo café (risadas), não desfaço de ninguém não. O pessoal também vai lá em casa, a gente conversa.......) que nem nesses dias aí, o, o, o meu vizinho lá tava muito doente mesmo, precisava ir pro hospital, coloquei ele em cima lá da moto e disse: "vambora, vixe, levo você lá". "Mas demora, é lá no Centro." "Mas não, vixe, você tá doente." Peguei ele, coloquei em cima da moto e ó, vazei pro hospital. Ainda fiquei até um pouco lá com ele, esperando os parente dele, mas não, não tem problema não. É um pessoal muito simpático mesmo." (Paulo)

Pelas observações e informações obtidas, foi possível perceber que esse jovem demonstra interesse em preservar sua imagem como a de alguém bem-relacionado com todos, tanto na Escola "Pestalozzi" como na Igreja que frequenta: "Nasci no bairro, bem dizer, conheço todo mundo nesse bairro.(...) Eu me dou bem..., eu sou animado." (Paulo). Acredita-se que esta seja uma estratégia para conseguir concretizar seu projeto, ou seja, abrir sua própria academia de capoeira, hipótese explicitada em alguns momentos de seu relato, quando diz, por exemplo:

"Voltei pra cá e consegui esse serviço no Carrefour e estudando... e agora dando aula de capoeira aqui. Vim de lá pra cá e sempre quis abrir uma academia aqui e... agora dando aula aqui no projeto aqui (...) o plano de nós dois (se refere ao seu amigo que também ensina capoeira) é montar uma academia pra nós (...)"(Paulo)

Num outro momento, afirma:

"O objetivo meu é esse no bairro, tô pretendendo abrir uma academia aqui, né. Não só aqui na 'Pestalozzi', mas arrumar um espaço pra mim montar uma academia aqui na região."(Paulo) 
Sua identificação com o bairro em que mora é diferente quando comparado às duas outras informantes, pois além de, durante 5 anos, ter viajado por algumas cidades de São Paulo e Rio de Janeiro, trabalha fora do bairro e possui, portanto, contato com diversos outros grupos sociais que não somente aqueles que residem na localidade:

"Eu costumo sair, costumo sim... porque sabe, no Carrefour, lá... a gente conhece bastante gente. Tem gente de vários bairro e de vem em quando eles convida pra ir numa festinha assim...eu vou em festa fora daqui, lá pro lado dos "Cinco Conjuntos"... lado do "Parigot" ", esses lado assim. Sempre se tá conhecendo gente assim de fora(...)"(Paulo)

Enquanto Paulo mantém relações também com outros grupos fora da região em que vive, Rosângela, pelo fato de não trabalhar fora, permanece a maior parte do tempo no local onde mora, inclusive nos finais de semana. Quando seu marido arruma serviço, ela fica sozinha com seus fillhos e raramente sai de casa. Esta senhora fala enfaticamente que é seu marido o responsável pela construção de sua nova casa e que ele tem feito isso sozinho, aproveitando quando está desempregado ${ }^{15}$. Fato que acaba por fazer, também, de tempos em tempos, parte da rotina desta família.

“(...) quando meu marido tá empregado, vai trabalhar. Quando não tá empregado ele trabalha em casa, na construção, né, quando ele tem material... Ele que faz, ele que mexeu, ergueu a casa e assim por diante, né. $O$ que for preciso fazer ele vai fazendo. Porque ajuda, nem dos meus irmãos a gente não tem aqui. E da minha casa sou eu que cuido, do meus filhos..." (Rosângela)

Sua casa atual, embora seja um barraco, mantém algumas características que nos remete à lembrança de uma residência de indivíduos

\footnotetext{
1+ "Cinco Conjuntos" é a designação dada a diversos conjuntos habitacionais (não somente a cinco) na região norte da cidade de Londrina, Parigot é um desses conjuntos.

${ }^{15}$ Cabe ressaltar que o material para a construção da casa dessa jovem senhora foi providenciado pelo programa assistencialista da Escola "Pestalozzi". Rosângela procurou "quitar" sua dívida dedicando alguns dias para ajudar na limpeza da Escola.
} 
com algum poder aquisitivo. Há objetos e enfeites decorando seu armário de cozinha que ameaça desabar, contrastando com a precariedade do restante dos móveis e da própria casa. Uma possível razão para isso talvez seja o fato desta senhora ter trabalhado, durante dois anos, como empregada doméstica num apartamento, no centro da cidade, onde recebia doações. Procurou dispor os objetos e enfeites de maneira tal que pudessem tornar sua casa, nem que fosse um pouco, semelhante ao ambiente onde trabalhava. De alguma forma, sua experiência como empregada interfere na maneira como ela se pensa e pensa os outros que fazem parte de seu cotidiano.

“(...) aqui neste lugar não dá muito pra gente ter amizade, porque é muita fofoca, né. A gente tem muito problema, porque tem vezes que a gente... é até um pouco diferente das outras pessoas e parece que as pessoas nã̃o aceita muito isso, né. Eles acham que você é muito exibida (...)" (Rosângela)

Em seu relato ela reconhece o conflito existente em suas relações sociais no bairro, afirmando:

“(...) tenho problemas com a vizinhança sim. Tem problemas com a demarcação do meu lote e também com os animais que tem na vizinha (...). Eu não tenho animal na minha casa. E tem vez que a gente nem sai pra fora, e tem carrapato na cama, na coberta, tudo, né. Então tem vez que até dá alergia na gente, faz ferida, tudo, dá coceira, né. E... meus filhos, deu até infecção no sangue deles e eu tô achando que é por causa disso, por causa do carrapatinho, por causa dos animais. (...) e também tem vez que meninos aí fumam droga. Não tenho nada a ver com isso, mas tem vez que prejudica a gente, né. Incomoda a gente." (Rosângela)

Há questões levantadas por Rosângela que sugerem reivindicações por melhorias no bairro que, segundo ela, deveriam ser iniciativa dos próprios moradores:

“(...) até a sujeira, sabe, acho que cada um deve de ter... ah, varrer a frente da sua casa para não entupir a rede de esgoto (...). Eu acho que deveria ser aplicado uma multa pra essas pessoas que não limpam a frente de suas casas e deixam seus fillos pegar 
pedra, pegar lata e jogar dentro das "boca-de-lobo", pra poder estragar.(...) Que daí é obrigação de cada pessoa, não é só do Prefeito, não é das pessoas que passam recolhendo esse lixo, vem de cada pessoa, dos moradores." (Rosângela)

Ao criticar a falta de cuidados dos moradores com a limpeza e com o lixo, Rosângela revela a precariedade de vida da população local.

Já a rotina diária de Dona Maria consiste em levantar cedo, ir trabalhar na Escola "Pestalozzi", almoçar em casa e retornar da jornada de trabalho ao anoitecer:

"Eu levanto seis horas. Daqui vou pro serviço faltando quinze pra sete. Que até eu chegar lá tem que abrir portão, abrir porta, sabe, daí eu vou cedo por causa disso. (...) Meio-dia eu venho armoçá. Uma hora eu vorto e chego em casa só de noite. Chego seis hora... o horário de eu largá é seis hora. Quando é dia de sopa $^{16}$, dia de Segunda e de Terça, eu chego mais tarde, daí tenho que ficar ajudando as muié lavar as panela, guardá tudo. Então eu nunca saio seis hora." (Dona Maria)

Dona Maria, assim como Rosângela, relembra o tempo em que as dificuldades encontradas na região eram muito maiores:

“(...) quando eu entrei aqui, tinha..., era a minha casa, aí outra vizinha aqui na quadra (...). Aqui era só capim, não tinha água, não tinha luz, não tinha nada. Eu tinha que carregá água dali de cima." (Dona Maria)

Sua mudança para o Jardim Franciscato ocorreu após a impossibilidacle de continuar vivendo numa chácara, onde trabalhava com seu marido no Parque das Indústrias. Saíram de lá sem terem onde morar e, para fazer sua casa, Dona Maria relata:

"(...) o homem lá da chácara que eu morava lá pegou dois cômodo que tinha lá e deu pra nós fazer aqui. Daí eu peguei..., daí meu marido pegou e fez os dois cômodo que eu entrei dentro..." (Dona Maria)

\footnotetext{
"Esse "dia de sopa" ao qual D. Maria se refere, é o dia em que voluntários preparam sopa ua cozinha da Escola "Pestalozzi" para distribuir à população residente na região. Isso ocorre às segundas e terças-feiras.

${ }^{17} \mathrm{Sr}$. José é um dos dirigentes da Instituição.
} 
Isso aconteceu há 18 anos e há 1 ano o departamento da Escola "Pestalozzi", que presta serviços assistencialistas para a comunidade local, providenciou material para a construção de uma nova casa para essa senhora. Dona Maria se mostra muito agradecida aos responsáveis pela construção de sua casa e também pelo seu emprego na Escola:

"(...) até essa minha casa que tava caindo, eles fizeram. Fizeram a minha casa, sabe?"(...) lá (se referindo à Escola-Oficina "Pestalozzi”) é a mesma coisa que eu tô na minha casa, eu gosto muito da Maria Heloísa, do seo José ${ }^{17}$, deles tudo, sabe. A mesma coisa que uma família. Eles me trata muito bem, eu não tenho o que recramá deles, sabe. (...) eu sinto lá a mesma coisa que eu estar na minha casa. Que já faz três anos que eu trabaiava lá (antes, como voluntária). Eu tenho as criança lá... é a mesma coisa que um filho pra mim. Então eu gosto muito de trabaiá lá.'(Dona Maria)

Essa senhora, assim como Rosângela, também passa a maior parte do tempo na região onde reside e trabalha, mas o contato que tem com diversas pessoas que não residem ali $^{18}$ a faz vivenciar e estabelecer relações sociais fora do bairro. Por um lado, desvia-se de assuntos relacionados a possíveis conflitos existentes com a vizinhança no cotidiano do bairro e região, afirmando, por exemplo: "Ah, eu gosto de morar aqui. O tempo que eu moro aqui, sabe, eu se dô com todo mundo" (Dona Maria). Também acentua os laços de solidariedade:

"Aqui é onde o povo já..., já fica unido pra vida. Porque que nem aqui: se tem uma "ruinha" lá, que precisa fazer um asfalto, aí o povo daqui tem que unir e ir lá pra ver o que "eles" pode fazer de melhor." (Dona Maria)

Por outro lado, aponta falhas na organização dos moradores de seu bairro (Jardim Franciscato), enfatizando a capacidade de mobilização da população do Jardim Novo Perobal, bairro vizinho, que vem conseguindo mais melhorias.

${ }^{18}$ Tais pessoas que não residem na região são as que prestam serviços voluntariamente na Escola. 
“(...) aquele ônibus ali, foi o presidente dali do Novo Perobal, foi lá, fizeram uma reunião, tudo, pra vir um ônibus. E você viu que o ônibus dali está escrito "Novo Perobal". Que nem ali, o ônibus ali, quem fez mais força pra vir um ônibus ali foi o Novo Perobal. Lá tem um presidente que é mais organizado e aqui... (...) nós pega ônibus porque o povo lá fez o pedido. Se não fosse eles, tava sem ônibus. (...) o presidente daqui, ele não faz uma reunião, não faz nada...(...) quando eu mudei pra cá, aquele Novo Perobal nem existia. E ali é mais unido o povo. Que nem ali, tem escritura das casas... e que nem aqui, a gente mora aqui mas não tem documento de uma casa. Que nós tem aqui? Nós não tem nada disso." (Dona Maria)

Tanto ela quanto Rosângela admitem que a fundação da Escola "Pestalozzi"constitui a única fonte de benefícios possíveis para a população local: "Aqui no Franciscato, a única benfeitoria que saiu foi a Escola-Oficina “Pestalozzi” (...)”(Rosângela)

É através da "Pestalozzi", do trabalho de voluntários da Comunhão Espírita e de projetos assistencialistas, culturais, de esporte e de lazer, que os moradores desses bairros conseguem garantir algum tipo de benefício econômico, assistência social, lazer, entre outros.

Apesar de Rosângela ter obtido junto a essa Instituição uma grande parte do material para construção de sua casa, por ser evangélica, não participa das palestras e reuniões oferecidas pela Instituição e também não permite que seus filhos participem de rituais próprios da doutrina espírita (que ocorrem aos sábados e domingos, durante a "evangelização"). No entanto, permite que suas crianças participem das brincadeiras, do lanche e das comemorações festivas na Escola reconhecendo, de forma positiva, o trabalho que a Instituição vem desenvolvendo junto à população da localidade.

Paulo também acentua a importância do assistencialismo desenvolvido pela Escola:

"(...) agora com a ajuda daqui da... da "Pestalozzi" assim, que tá sempre ajudando assim, acho que melhorou bastante mesmo, porque pode ver esse lado das pessoas. Tem muita gente que é pobre mesmo, que precisa mesmo(...). Muita gente que tá sem trabalhar, gente que não consegue se aposentar, porque tá muito difícil, né. E... acho que a "Pestalozzi" tá fazendo um trabalho muito importante aqui pra gente, né.” (Paulo) 
Na realidade, observou-se que a Escola-Oficina "Pestalozzi" se tornou uma clara referência entre as pessoas da região. Um centro em torno do qual os moradores da região se organizam, reivindicam, criam redes de sociabilidade, prestam serviços e usufruem de outros benefícios através de práticas sociais e cotidianas, a fim de suprir muitas de suas carências materiais. A intenção deste trabalho, porém, não é analisar esta estruturação realizada no interior da Escola mas, sim, o cotidiano fora dela, nos próprios bairros. A Escola, é importante ressaltar, foi o ponto de partida para a pesquisa e para ela retorno com freqüência, com a finalidade de apreender as relações com os moradores da região.

Como foi possível observar, enquanto muitos moradores apresentam falta de perspectiva em relação à vida que levam, outros encontram formas para suprir suas necessidades e até mesmo superar as dificuldades de sobrevivência através de estratégias específicas, como nos casos observados (Rosângela, Paulo e Dona Maria). Suas informações acrescidas de outras obtidas com diversas pessoas e, também, as observações diretas, nos revelam alguns fragmentos que constituem parte do cotidiano das pessoas da região em estudo.

Como já foi explicitado, conforme Caldeira (1984) e Durham (1986), existe um ritmo, estilo e tipo de vida que são próprios daqueles habitantes, bem como valores que são compartilhados por eles. Há uma determinada rotina que resulta em identificação de valores, hábitos, gostos e aspirações, mesmo exercendo diferentes atividades no mercado de trabalho, - que é o que os torna heterogêneos, como se verifica nos casos de Rosângela, Dona Maria e Paulo. As carências materiais os colocam em condições de vida muito semelhantes que, segundo Durham (1986), possivelmente, geram características culturais específicas e diferentes

\footnotetext{
${ }^{19}$ Na obra Subúrbio do autor Martins (1992) diz: "O subúrbio está proposto, entre nós, como o lugar da reprodução e não como lugar da produção: como lugar da repetição e não da criação; como lugar do cotidiano e não da História (...). É lugar para morar e trabalhar. Nesse sentido, é também lugar do vivido (mas, do vivido fragmentado) (...). Lugar do nada é, também, lugar da procura da memória”(p.15)

${ }^{20}$ De acordo com Ágnes Heller: "(...) os homens jamais escolhem valores, assim como jamais escolhem o bem ou a felicidade. Escolhem sempre idéias concretas, finalidades concretas alternativas concretas." (HELLER. 1989. p. 14).
} 
daquelas sentidas por aqueles que não vivenciam a mesma situação socioeconômica em outros locais da cidade. Em periferias, a sociabilidade tende a ser produzida num relativo isolamento, pois acaba constituindo um estilo de vida próprio, "(...) marcado por uma peculiar mentalidade suburbana" (MARTINS, 1992) ${ }^{19}$.

A partir dos valores que estes indivíduos compartilham ${ }^{20}$, estrutura-se um cotidiano específico, cuja noção de tempo é repetitiva e cíclica, por se iniciar, terminar e recomeçar da mesma maneira (CALDEIRA, 1984). Enquanto isso ocorre discretamente, sem que se dê grande importância ou atenção, temos a noção de tempo que prevalece em nossa sociedade, que se baseia na sequência cronológica e linear.

As relações sociais predominantes no local em que foi feita a pesquisa são, como já foi dito, de vizinhança, cuja tendência é a identificação dos indivíduos com o local onde moram (MARTINS, 1999). Mas, como também já foi explicitado, estas relações implicam um tipo de sociabilidade caracterizada por uma certa ambigüidade, porquanto ao mesmo tempo que as pessoas vivem próximas, a luta por interesses específicos resulta, muitas vezes, em tensões e conflitos nem sempre aparentes.

Recorrendo a Goffman (1985, p.18), podemos dizer que há, entre os moradores, um "consenso operacional", que consiste num:

"(...) acordo real quanto às pretensões de qual pessoa, referente a quais questões, que serão temporariamente acatadas. Haverá também um acordo real quanto à conveniência de se evitar um conflito aberto de definições de situação."

Esta idéia nos remete aos casos de Dona Maria e Paulo que, em seus relatos, se esquivam de questões do cotidiano relacionadas a conflitos na vizinhança, por estarem justamente evitando um conflito aberto. Mas, na realidade, o conflito está sempre presente, como em qualquer relação social, a exemplo do que ocorre com Rosângela, que traz à tona diversos casos conflituosos que vivencia ou presencia, inclusive na Escola "Pestalozzi":

“(...) ali tem muito ciúmes, né. Porque a gente tem... até eu, tem vezes, né. A gente não pode falar só dos outros. Eu também, tem vez que eu sinto ciúme (...). Mas tem muita fofoca, tem muita 
inveja ali na Escola. Tanto que quando eu consegui que me ajudassem aqui, foram lá e falaram que não era eu que cuidava dos meus filhos, que quem cuidava dos meus filhos era minha mãe. E que... e foram lá também e falaram que eu não precisava de ajuda pra construir minha casa porque minha mãe podia ajudar (...)."(Rosângela)

Como também já apresentamos, utilizando a linguagem teatral como meio para análise dos processos de interação social proposto por Goffman (1985), podemos dizer que entre os moradores existe a preocupação de preservar uma imagem, evitando de ser mal-interpretados num lugar onde todos se conhecem (como é o caso do bairro em que vivem). De acordo com esse autor, os personagens, encarnam um papel cuja atuação prevê o convencimento e a aceitação daqueles que a ele assistem. A vizinhança, que acaba se tornando parceira dos atores envolvidos nessa relação de identificação com pessoas e com o lugar, neste caso, é a platéia que atentamente assiste ao que é encenado no palco.

O palco é o lugar das representações, é onde um ator profissional interpreta um papel mas que, na vida real, age de maneira diferente. As pessoas representam o que pensam que são (GOFFMAN,1985). Este autor afirma que é nos bastidores que o indivíduo se sente mais à vontade, pois é o lugar onde os atores tiram suas máscaras. Assim, acreditamos que Dona Maria e Paulo não removem as máscaras quando fazem declarações a respeito de seus serviços prestados na "Pestalozzi" ou sobre o bairro em que residem, por precisarem, de alguma forma, desempenhar bem seus papéis na encenação. Pois, segundo Martins (1999, p. 13-14):

"As situações sociais nos falam de encenações que devem ser cumpridas por meio de diferentes desempenhos e nos falam também , da corresponsabilidade dos atores nesses desempenhos."

Enquanto Dona Maria desempenha seu papel há 2 anos, porque ela necessita do emprego, existem muitas outras pessoas que atravessam dificuldades semelhantes às suas - Paulo iniciou sua representação há pouco tempo, tendo por isso que "mostrar trabalho" (suas próprias palavras) caso queira levar adiante seu projeto de vida.

No caso de Rosângela é possível identificar fronteiras tênues entre a representação no palco e na sua vida por trás dos bastidores. Ela 
não precisa garantir mais nada, por já ter obtido a maior parte daquilo que necessitava, graças a sua aproximação com a Escola "Pestalozzi".

Rosângela apresenta posições diversas daquelas observadas e assumidas entre os moradores da região e também dos freqüentadores da "Pestalozzi". Por um lado, ela própria se marginaliza em relação às várias propostas feitas pela Escola (não aceitando a doutrina espírita, por exemplo) e em relação à dinâmica do próprio bairro, não mantendo contato frequiente com vizinhos, nem permitindo que seus filhos brinquem com outras crianças ou que frequientem a creche. Marginaliza-se também em relação ao mercado de trabalho deixando com isso de ajudar no orçamento de sua família. Por outro lado, contraditoriamente, essa jovem deixa transparecer a importância da Instituição para a sua sobrevivência - e de sua família -, foi com a ajuda dessa Instituição que ela conseguiu construir sua casa:"(...) se não fosse lá, nós não tínhamos erguido ali a nossa..., os dois cômodos...” (Rosângela)

\section{Considerações finais}

Pelos relatos dos informantes e pelo que foi observado direta e indiretamente da vida cotidiana dos bairros em questão, vemos, por um lado, os indivíduos se identificando com o local de moradia, através de uma interação social estruturada em ambientes de pequena escala (grupos de parentesco, relações de vizinhança, e de amizade) e, por outro lado, numa escala maior, vemos a construção de sua existência social realizada cotidianamente, através do trabalho e relações fora do bairro.

Assim podemos nos reportar a Heller (1989, p.19)., quando define a vida cotidiana como "(...) o conjunto de atividades que caracterizam a reprodução dos homens particulares, os quais, por sua vez, criam a possibilidade da reprodução social".

Porém, não sendo viável essa reprodução, Martins (1998) afirma que é este o momento em que se instauram a invenção, a ousadia, o atrevimento e a transgressão, já que é quando há rupturas do cotidiano. Assim, a transformação da vida destes indivíduos poderia ser efetivada. Só quem tem "necessidades radicais"2! pode desejar e fazer tal transformação, porquanto trata-se de: 
"(...) necessidades que ganham sentido na falta de sentido da vida cotidiana. Só se pode desejar o impossível aquele para quem a vida cotidiana se tornou insuportável, pois esta vida já não pode ser manipulada." (MARTINS,1998, p.6) (2- $^{22}$

Mesmo sem terem realizado qualquer transformação social mais significativa, foi possível verificar nas estratégias adotadas por Rosângela, Paulo e Dona Maria que, embora de maneiras diferentes, todos excogitam e procuram meios de obter aquilo que necessitam. Essas estratégias eles montama na vivência do dia-a-dia, quando surgem carências imediatas. Assim, podemos afirmar como Martins:

“(...) o novo herói da vida é o homem comum imerso no cotidiano. É que no pequeno mundo de todos os dias está também o tempo e o lugar da eficácia das vontades individuais, daquilo que faz a força da sociedade civil, dos movimentos sociais."(MARTINS,1998, p.2)

Este autor se refere, portanto, ao homem comum, portador de um senso comum. Mas esclarece que este senso não é comum por que é banal, destituído de verdade ou repleto de equívocos e, sim, por se tratar de um conhecimento compartilhado entre os sujeitos da relação social. Esse conjunto de anônimos forma a base da sociabilidade moderna. Daí o interesse sociológico por estudos sobre a vida cotidiana na atualidade. Martins ainda propõe trazer para as Ciências Sociais, “(...) a realidade de um mundo ocultado pelas grandes categorias explicativas e pelas grandes abstrações (...), o drama e a trama da sociabilidade dos simples."(MARTINS, 2000b, p.135). Portanto, sua proposta metodológica e teórica baseia-se na observação da sociedade a partir da margem,

2t Termo utilizado por Agnes Heller (apud Granjo, 1996) para indicar a necessidades de elementos qualitativos da vida social.

22 Com essa visão acerca dos momentos de rupturas do cotidiano. Heller (apud GRANJO,1996) e Lefebvre (1991) também apontam para os momentos de criação que se instauram. Ainda segundo Heller, as necessidades radicais às quais se refere, são assim denominadas porque não podem ser satisfeitas sem profundas transformações sociais. (MARTINS, 2000a) 
“(...) do mundo cinzento daqueles aos quais as contradições da vida social deram a aparência de insignificantes e que como insignificantes são tratados pela ciência. E, no entanto, se movem..."

Naqueles bairros encontram-se, por um lado, indivíduos com dificuldades por falta de alimento, remédios e vestimentas; problemas com a precariedade de suas moradias, com a infra-estrutura nos bairros e com a regularização dos lotes junto à Prefeitura tendo, em seu dia-a-dia, a dura tarefa de criar meios para sobreviver. Por outro lado, há aqueles que, aos poucos, conseguem superar todas estas dificuldades, passando, assim, a almejar outras. Portanto, apesar da precariedade em que vivem, estes indivíduos buscam meios para obter aquilo que necessitam, através de estratégias montadas em suas práticas sociais e cotidianas.

Não obstante a atuação do poder público local, através da Secretaria de Ação Social e também da Escola-Oficina "Pestalozzi", esta última com uma participação bem maior naquela comunidade, fornecendo cestas básicas, roupas, medicamentos, cursos profissionalizantes, esporte, arte e lazer, entre outros, é evidente que não se atende a todos. Mas, graças a sua atuação no bairro, a Instituição é avaliada positivamente por muitos moradores, visto que é através dela que suprem suas carências materiais mais imediatas.

O que se verifica nesses bairros e que talvez esteja se generalizando nas demais periferias de qualquer cidade de grande ou médio porte é que a margem deixada para a "vida" e para a "beleza" é muito estreita. Este "homem comum", cuja voz é insistentemente calada, trava em seu cotidiano uma luta ininterrupta para suprir carências materiais imediatas.

Mesmo assim, por mais que temam a perpetuação da miséria, pulsa a vontade de viver e sobreviver, ultrapassando os limites impostos pela situação socioeconômica em que vivem. Nesse sentido, o local de moradia emerge ao mesmo tempo como espaço de "sobrevivência" e de construção de identidades individuais e coletiva. Porém, esta é uma questão que poderá ser discutida em outro tempo e em outro lugar. 


\section{Referências Bibliográficas}

ADUM, Sônia. Imagens do Progresso: Civilização e Barbárie em Londrina: 1930/ 1960. 1991. Dissertação (Mestrado em História) - UNESP. Assis.1991.

CALDEIRA, Tereza P. do R. A política dos outros. O cotidiano dos moradores da periferia e o que pensam do poder e dos poderosos. São Paulo: Brasiliense, 1984.

DURHAM, Eunice. A sociedade vista da periferia . Revista Brasileira de Ciências Sociais, São Paulo, v.1, n.1, p. 84-99, jun.1986.

ELIAS, Norbert..Os Estabelecidos e os Outsiders (As Relações de Poder de uma Pequena Comunidade). Rio de Janeiro: Jorge Zahar, 2000.

Sobre o tempo. Rio de Janeiro: Zahar, 1998

GEERTZ, Clifford. A interpretação das culturas. Rio de Janeiro: Zahar. 1978.

GOFFMAN, Erving. A representação do eu na vida cotidiana. Petrópolis: Vozes, 1985.

GRANJO, Maria Helena B. Agnes Heller : Filosofia, Moral e Educação. Petrópolis: Vozes, 1996.

HELLER, Ágnes. O cotidiano e a história. Rio de Janeiro: Paz e Terra, 1989.

LEFEBVRE, Henri. A vida cotidiana no mundo moderno. São Paulo: Ática. 1972.

MARTINS, José de Souza. As mudanças nas relações entre a sociedade e o Estado e a tendência à anomia nos movimentos sociais e nas organizações populares. Revista Estudos Avançados, São Paulo, v. 14, p.268-278, Jan./ Abr.2000a.

A Sociabilidade do homem simples: cotidiano e história na modernidade anômala. São Paulo: Hucitec, 2000 b.

O senso comum e a vida cotidiana. Revista Tempo Sócial: Revista de Sociologia da USP, São Paulo, v.10, p.1-8, maio. 1998.

187, 1997. Entrevista

Sociologia e militância. Estudos Avançados, v.11, n.31. p.137-

Subúrbio: vida cotidiana e história no subúrbio da cidade de São Paulo: São Caetano, do fim do Império ao fim da República Velha. São Paulo: HUCITEC, 1992.

HUCITEC, 1999.

Vergonha e decoro na vida cotidiana da metrópole. São Paulo: 
RAZENTE, Nestor. Ocupação do Espaço Urbano de Londrina. Dissertação (Mestrado em Arquitetura e Urbanismo. Dissertação de Mestrado em Desenvolvimento Urbano e Regional). Recife: Universidade Federal de Pernambuco, 1982.

SILVEIRA. Ricardo de Jesus. As Associações de Moradores e a Construção do Espaço Público: un exercício de cidadania (estudo sobre o movimento de Associações de Moradores de Londrina). 1997. Tese (Doutorado em Sociologia) - USP, São Paulo, 1997

TEDESCO, João Carlos. Paradigmas do cotidiano: introdução a constituição de um campo de análise social. Santa Cruz do Sul: EDUNISC, 1999.

\section{Abstract}

This paper refers to a research about the organizing of nets of sociability among the people from Londrina's outskirts. My intention is to emphasize how these dimension sociability and daily life, come up as important sociological categories in studies about the outskirts.

Key-110rds: daily life; outskirts; sociability. 